\title{
Frequency of using additional coefficients during the engineering-and-technical investigation of buildings
}

\author{
Ivan Doroshin*, Aleksandr Perunov \\ Moscow State University of Civil Engineering, 129337, Moscow, Russia
}

\begin{abstract}
For definition of cost of works on the engineering technical investigation we need to apply some correcting coefficients presented in the article. These coefficients are recommended and show the difficulty of real investigation. We have found some other coefficients, that reflect the conditions of investigation more exactly, based on real works in certain investigation organization, that are not recommended in standards. For each coefficient we bring the frequency of its use, based on the data of certain organization. If the coefficient is used rather often but not always, we think it possible to obtain the right value of the coefficient. The obtained results for the coefficients are compared to the new regulatory documents. The comparison lets us say, that coefficients, brought in different documents vary. Moreover, for certain cases, met rather often in the practice of investigation, there are no coefficient in the recommended sourcebook. So we propose to create the common system of coefficients, based on statistics of several investigative organizations.
\end{abstract}

\section{Introduction}

Engineering-technical investigation is a very important part of pre-design works. These works give the necessary information for working out of construction design, we obtain the information about condition of soils, ecological situation in the place of supposed construction, etc. The information we obtain from engineering-technical investigation is physical condition of construction, defects, their bearing capacity, strength of materials, sometimes geometric drawings of buildings, etc. We also need to determine the cost of these works.

We wrote earlier about the determination of coefficients and rates on engineeringtechnical investigation on the basis of certain organization data about the time, spent on investigation, and about quantity of specialists of each category, having different wages, taking part in the process of investigation. But we also need to find out the system of these coefficients, which coefficients we use often and which we practically never touch. These data will provide us the information about correctness of determination of specific coefficients in the specific organization.

\footnotetext{
* Corresponding author: ivandoroshin@rambler.ru
} 


\section{Materials and methods}

The methods, used in this article, are based on study and analysis of the existing literature and previous works on the theme, as well as accepted regulatory documents, which served to understand the problem and possibilities of its decision, using the cost and finance data of real firms. Having understood, that such determination is possible, we tried to analyze the statistic data of certain organizations to receive the necessary parameters - validity and frequency of use, as well as the structure of coefficients, that may be used at definition of cost of investigative works.

\section{Results}

On the basis of work in a specific organization, conducting the investigation works we may state, that not all the coefficients from corresponding sourcebooks are used, between the objects, explored by the laboratory, there have been no objects with rooms, dangerous for health and with temperature more than $30^{\circ} \mathrm{C}$.

In the sourcebook of MRR [4], used for definition of engineering-technical investigation cost there is a system of coefficients, reflecting the factors, simplifying and complicating the investigation, and increasing or diminishing the cost of works:

Table 1. Cost coefficients used for account of investigation factors

\begin{tabular}{|c|c|}
\hline Name of coefficient & Value \\
\hline 1.Special regime of object & 1.15 \\
\hline $\begin{array}{l}\text { 2. Increased labor expenses during investigation: } \\
\text { a) investigation in places, dangerous for health }\end{array}$ & 1.0 \\
\hline b) investigation in hot places and rooms with humid atmosphere & 1,10 \\
\hline c) investigation of high constructions, for which special devices are necessary & 1.15 \\
\hline $\begin{array}{l}\text { d) winter period of time, also investigations at temperature lower } 0^{\circ} \mathrm{C} \text {, external } \\
\text { or internal constructions }\end{array}$ & 1.20 \\
\hline $\begin{array}{l}\text { e) complication of the works because of great quantity of facility and furniture } \\
\text { in rooms }\end{array}$ & 1.10 \\
\hline $\begin{array}{l}\text { 3.The historical and cultural value of the investigated buildings, complicating } \\
\text { the investigation }\end{array}$ & 1.20 \\
\hline 4. The place is out of Moscow, and demands special expenses for transport & 1.15 \\
\hline $\begin{array}{l}\text { 5. Less constructive volume: } \\
\text { a) under } 1000 \mathrm{~m}^{3}\end{array}$ & 2.5 \\
\hline b) under $2000 \mathrm{~m}^{3}$ & 2.2 \\
\hline c) under $3000 \mathrm{~m}^{3}$ & 1.8 \\
\hline d) under $4000 \mathrm{~m}^{3}$ & 1.4 \\
\hline e) under $5000 \mathrm{~m}^{3}$ & 1.2 \\
\hline f) $5000 \mathrm{~m}^{3}$ and more & 1.0 \\
\hline 6. Works on contract conclusion & 1.04 \\
\hline $\begin{array}{l}\text { 7. The investigating organization has previous drawings, which are used and } \\
\text { verified }\end{array}$ & 0.75 \\
\hline 8. There are no verifying calculations of constructions & 0.8 \\
\hline $\begin{array}{l}\text { 9. The measuring of constructions is not carried out, investigators have the } \\
\text { floor plans, which are checked and the visible defects of constructions are } \\
\text { marked on them, usually the defects of floor coverings and sometimes of walls } \\
\text { and columns }\end{array}$ & 0.75 \\
\hline $\begin{array}{l}\text { 10. The brickwork condition in the foundations is not verified, and strength of } \\
\text { brickwork is not determined in the open excavations, when it is not necessary } \\
\text { for the investigation }\end{array}$ & 0.8 \\
\hline In case one of work steps is conducted & 0.9 \\
\hline
\end{tabular}


These coefficients aren't used with the same frequency. Some are used practically in every object, some - rarely. There are many organizations in our city, that perform the investigative works. Each organization has its specific structure of objects and specific set of coefficients. For example if you investigate the living buildings, you will scarcely use the coefficient "dangerous production", because there is no production at all. So every organization must have the opportunity to calculate its own, frequently used coefficients.

On the basis of the statistic data for any organization, we must be able to calculate the value of certain coefficients. Using our methodic, we will obtain the best results, if a coefficient calculated has the frequency of use about $50 \%$. On the basis of data of the laboratory "Investigation and reconstruction of buildings and structures" of our university we will try to analyze the structure of coefficients used. Using the data of the laboratory, we can obtain the frequency of the coefficients, brought in Table 1. For the analysis we will consider no less than 100 estimates on real works.

The analysis of statistic data of the laboratory give us the next frequency of the cited coefficients, reflecting the complicating factors:

- coefficient "small volume" is used in $45 \%$ of investigations;

- coefficient «cold weather» - $28 \%$, really $30 \%$ of investigations are carried out in winter, exactly from November to March;

- coefficient "high constructions" - 85\%;

- coefficient "presence of facilities and furniture"- $81 \%$;

- coefficient «contract conclusion works»-91\%;

- coefficient «previous drawings» $-32 \%$;

- coefficient «special regime»- $9 \%$;

- coefficient «historical and cultural value» (historical monument) - $13 \%$.

The results you may see in figure 1 The most frequent coefficients are "use of stairs for high constructions", "presence of furniture or facilities", "works on contract conclusion", sometimes we use "small volume of buildings", "winter time" and "available drawings", and frequency of "cultural value" and "special regime" is low.

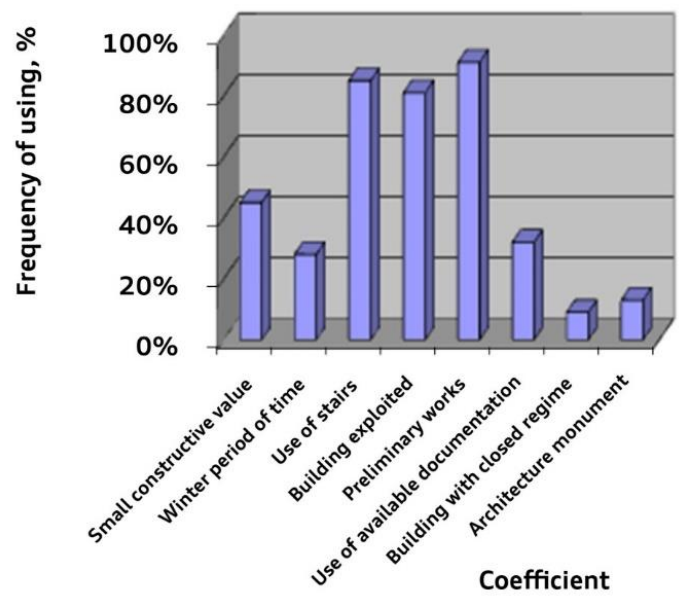

Fig. 1. Distribution of frequency of using of coefficients

For our methodic it would be better, if we had frequency about $50 \%$, so the best coefficient in that sense is "small construction volume", it is used in 50 objects approximately.

If a coefficient is used seldom or very often, its correct determination is under the question, because one of the groups, where it is present or is not present, will be small. According to the methodic of its calculation, it will not give correct result. Let us 
remember, that we need 100 objects (building or structures), where we have or have not this coefficient, or, more simply, we must have approximately 50 buildings, where it is applied. Besides, some coefficients are not present in the sourcebook, but the organization may use them. It is very often found in practice. For example in our case there were coefficients "using PC treatment of materials" and "special transport expenses". Thus, the coefficient on special transport was taken from the sourcebook on engineering geological works, and included in investigative works, because it reflects the real labor expenses.

Some coefficients, as we told earlier, are never touched by the laboratory. They may be calculated by other organizations, which use them. These are the coefficients "investigation in places, dangerous for health", "investigation in hot places and rooms with humid atmosphere", "The place is out of Moscow, and demands special expenses for transport", "measuring of constructions is not carried out, investigators have the floor plans, which are checked and the visible defects of constructions are marked on them, usually the defects of floor coverings and sometimes of walls and columns", "brickwork condition in the foundations is not verified, and strength of brickwork is not determined in the open excavations, when it is not necessary for the investigation".

Here we must observe, that determination of the coefficients by different organizations mustn't be done in vain, and used only by these organizations. There is absolute need in these coefficients being included in sourcebook, kept and recalculated with the passage of time.

Also we must say, that the coefficients, not included in the sourcebook, but used by the laboratory, have the next frequency of their appearance:

- "special transport expenses" - 28\%;

- "using PC treatment" - 57\%;

- "modeling of stress-strain state" - $62 \%$.

So we can obtain results practically for all the coefficients by our methodic, and they will be correct.

The information about these coefficients is in the Fig.2. We have to stop in detail on the real additional time expenses, that are represented by the additional coefficients. Thus the "special transport expenses" coefficient reflects not only the transit of investigation specialists to the building, that is realized in practice 5-10 times, but also delivery of survey equipment to the object. Sometimes that consists rather significant expenses. The transport expenses may be external or internal. External transport expenses must be accounted, when the investigated building is situated in other city or region, transportation to which takes more than several hours, the special base of investigation is created, that provides daily transfer to the object. There is also internal transport expenses, that are present in every object, even if it is in Moscow, not only out of the Moscow city.

Also the special calculation is necessary to verify the bearing capacity of constructions. It practically takes more time and labor, than $20 \%$ of investigative works. So we use the coefficient "modeling of stress-strain state" or "additional verifying calculations", that amounts $20-60 \%$ of investigative works. Sometimes calculations are conducted without the process of investigation of building or structure. That case also suppose carrying out of project expertise. For the calculation of building construction engineers use special computer programs for 3D modeling of constructions, calculation on different cases of loading of bearing elements of the building. The calculations are necessary in case of superstructure, extension of the building, changes of actual loads, applied to the constructions.

There is also the coefficient "Treatment of materials with PC" that was included earlier in estimates for the engineering investigation. It is absolutely clear in the current moment, that there is no investigations and scientific reports without computer and the coefficient, determined by Gosstroy of USSR in 1990 has no right on living. 


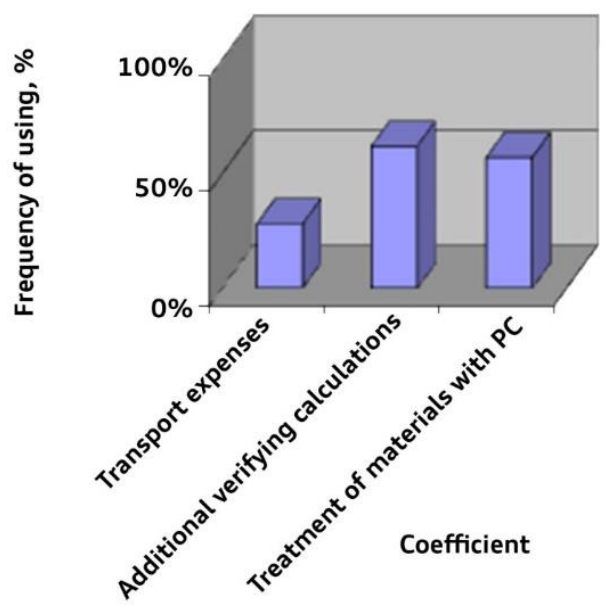

Fig. 2. Frequency of using for additional coefficients

So we can say, that not all the coefficients, given in the reference book, are used in all the organizations, and in the same time for many organizations at investigations the additional costs exist, that are not expressed with coefficients in the reference book. That's why the working out of the methodic of reasoning and including of additional coefficients, used by specific organizations, is very important, as well as of their calculation based on statistic data.

It's also necessary to note, that in the process of investigation the verifying calculations of building constructions take special place. Not only the existing building constructions are verified in the process of investigation for definition of sufficiency of their bearing capacity and its reserves, if they take place, but also the newly designed for reconstruction for the purpose of finding of optimal constructive decisions.

The verifying calculations usually follow the process of engineering-technical investigation, being its part, because they usually answer the question, are the investigated constructions suitable for further exploitation according to the defects and damage, found during investigation. Yet in technical specification the check of stress-deformation condition of constructions may be specified without carrying out of investigation, in case the geometric parameters of constructions checked are presented in design, or the condition of constructions doesn't cause concerns, in particular if the newly designed constructions are checked. This includes also the case of project expertise, when there is a task to study the design documentation and to make the conclusion about the correctness of constructive decisions, made in the design analyzed.

In the existing sourcebook MRR [4], determining the cost of engineering-technical investigation, there is only one indication concerning the verifying calculations, exactly, it says, that the cost of investigative works must be multiplied by coefficient 0.8 , if the checking calculations are not performed. From this estimators draw the conclusion, that the cost of checking calculations amount to $20 \%$ from the investigation cost. In reality the modern checking calculations are more complicated, than checking of certain constructions by standard simple formulas. They use complex automated system of verifying of bearing capacity of building constructions, including the calculations of the whole building by spatial system, 3D calculations of certain constructions considering current deformations, defects and damages, often the analyzed 3-dimensional constructions, buildings and structures are much greater complicated, than buildings provided by standard scheme, from which certain beams or wall elements are checked. 


\section{Discussion}

The document [4] is not the latest recommended sourcebook for determination of the cost of engineering-technical investigation. There is also sourcebook of basic prices $[5,6,7]$, that was issued in 2016 and is recommended now for calculation of the cost of investigation. The table 1, taken from [4], was changed, and the new coefficients has been added.

To begin with, let's consider the coefficients, that have disappeared from the table for calculation of the influence of the complicating factors. In the new sourcebook there is no coefficient number 4 "The place is out of Moscow", because this regulatory document is not only for Moscow city and can be applied for investigation in different parts of Russian federation. But we can suppose, that investigation specialists and organizations are not present in every town and city of our great country. Especially sometimes the very qualified specialists are demanded for special and unique structures and buildings. There are many cases, when the MSUCE laboratory carried out investigations in other cities, sometimes because it had more accurate equipment. On the basis of this fact we think, that the coefficient for external transport expenses is also necessary in all regions and parts of our country.

There is no coefficient on preliminary works (number 6). Sometimes the expenses for calculations of estimates and preparation of contract are rather considerable, the contract is not always signed and these works may be conducted without payment and only in the cases, when the contract is signed the specialists on estimates can receive some humble pay for their real efforts. We think that absence of this coefficient will conduct to the situation, when not all the labor expenses of the investigative organization will be taken into account.

The verifying calculations aren't mentioned at all, so there is no way of determining their price, even indirect. And before we wrote, that it is a very important part of the investigation, and it is absolutely necessary to find the way of definition of its cost.

The point 7 considers the situation, when investigation specialists have previous drawings, and there is no such point in the new sourcebook. The situation is encountered often, and simplifies really the process of measuring of constructions. In this case the Customer suffers, because if the organization has the drawings and gives them to Contractor, the price may be considerably diminished, that regards not only plans, facades and sections, but the coverings beams and slabs too. Sometimes the measuring is not included in investigation, and the investigation specialists draw the defects on schemes of constructions. This situation was described in the point 9 , and is not present in the new document, though it is often encountered at investigation process.

The point 10 told, that condition of the brickwork of foundations may not be checked, and the strength of brickwork may not be determined, if it is not necessary. The point is missed in the new sourcebook. There are many buildings in Russia, that has brick foundations, and they are not always checked.

There are new coefficients that consider the situation, when:

- the buildings were erected on drawdown, swelling soils, over the mountain excavations, in underflooding regions with karst and landslip occurrences;

- work performance in buildings with weak, medium and high degree of aggressiveness of environment;

- the seismic activity in the region is 7-9 points;

- the constructions were reinforced by previous designs.

\section{Conclusions}

These situations may be really encountered and demand special exploration. 
Therefore, considering all the reasons, brought above, we have to say, that it is necessary for correct definition of the cost of engineering-technical investigation to solve, which coefficients to use in the different situations of investigative works. It is also necessary to define, in which cases we can define their value on the basis of data of specific organization. Then it will be possible to try to build the system of determination of the value of coefficients, found on the statistic parameters of different investigative organizations.

\section{References}

1. I. Doroshin, Journal of Economy and entrepreneurship 5-1 82-1 (2017).

2. I. Doroshin, Estimate and contract work in construction 3 18-23 (2015).

3. GUP «NIAZ», Procedure of determining of the cost of works on technical investigation of constructions of buildings and structures (Moscow, Moscow Architecture Committee, 2000)

4. GUP «NIAZ», Recommendations on determining of the cost of works on investigation of technical conditions of constructions of buildings and structures MRR-3.2.05.03-05, Moscow, GUP «NIAZ», 2006.

5. T. A. Verminskaya, Almanac of modern Science and Education 7 37-39 (2008).

6. Sourcebook of basic prices on measuring works and investigations for buildings and structures SBCP 81-2001-25 (Moscow, 2016).

7. Sourcebook of prices for measuring-investigative and design works for capital repair of buildings and structures (Moscow, MHM, 1991). 